\title{
A PRÓPOLIS E SUA UTILIZAÇÃO EM ANIMAIS DE PRODUÇÃO
}

\author{
PROPOLIS AND ITS USE IN PRODUCTION ANIMALS
}

\author{
Coelho, M. de S. ${ }^{* 1}$, Silva, J.H.V. da ${ }^{2}$, Oliveira,E.R.A. de ${ }^{1}$, Amâncio, A.L.L. ${ }^{1}$, Silva, N.V. da ${ }^{1}$ \\ e Lima, R.M.B. ${ }^{1}$
}

\begin{abstract}
${ }^{1}$ Departamento de Zootecnia. Universidade Federal da Paraíba (CCA/UFPB). Campus Universitário. CEP 58397-000. Areia-PB. Brasil. *marcia.s.coelho@gmail.com

${ }^{2}$ Departamento de Agropecuária. Ciências Humanas, Sociais e Agrárias. Universidade Federal da Paraíba (CCA/UFPB). Campus Universitário. CEP 58220-000. Bananeiras-PB. Brasil.
\end{abstract}

\section{PALAVRAS ChaVE ADICIONAIS}

Apicultura. Extrato de própolis. Índices zootécnicos.

\section{RESUMO}

A própolis é um produto natural utilizado durante séculos pela humanidade e administrada sob diversas formas. Sua utilização ocorreu como apiterápico há séculos na medicina popular como agente antiinflamatório. Já foram identificados mais de 200 compostos químicos, de modo geral, a própolis contém $50-60 \%$ de resinas e bálsamos, $30-40 \%$ de ceras, $5-10 \%$ de óleos essenciais, $5 \%$ grãos de pólen, além de microelementos como alumínio, cálcio, estrôncio, ferro, cobre, manganês e pequenas quantidades de vitaminas $B 1, B 2, B 6$, C e E. A própolis é conhecida principalmente, por suas propriedades antimicrobiana, antioxidante, antiinflamatória, imunomodulatória, hipotensiva, cicatrizante, anestésica, anticancerígena, antiHIV, e anticariogênica. As investigações sobre as propriedades antibióticas da própolis têm sido conduzidas sobre tudo na área médica e veterinária, onde o produto tem demonstrado uma eficiente atividade bacteriostática e bactericida em relação a diversos gêneros de bactérias, porém poucos trabalhos, de ordem zootécnica, têm sido realizados, considerando-se as respostas dos animais, relacionadas a algumas dessas atividades biológicas.

\section{SUMMARY}

Propolis is a natural product used by humanity during centuries and is administered in many forms. Its usage occurred centuries ago as an apiarian therapy in popular medicine used as an

\section{AdDitional KEYWORDS}

Beekeeping. Extract of propolis. Zootechnical indexes.

anti-inflammatory agent. More than two hundred chemical compounds have already been identified in propolis. In general, propolis contains $50-60 \%$ resins and balsams, $30-40 \%$ waxes, $5-10 \%$ essential oils, $5 \%$ pollen grains, aside from microelements such as aluminum, calcium, strontium, iron, copper, manganese and small amounts of vitamins B1, B2, B6, C and E. Propolis is known mainly for its anti-microbe, antioxidant, anti-inflammatory, immunomodulatory, hypotensive, healing, anesthetic, anticancer, anti-HIV, and anti-caries properties. Investigations about the antibiotic properties of propolis have mainly been conducted in medical and veterinary medicine areas, where the product has demonstrated efficient bacteriostatic and bactericidal activity in relation to many types of bacteria, however few zootechnical researches related to these biological activities of propolis have been carried out considering the responses of animals.

\section{INTRODUÇÃO}

A própolis é uma substância resinosa, balsâmica e gomosa produzida pelas abelhas proveniente em primeira instância de exsu-dações vegetais, tais como resinas e líquidos secretados durante o desenvolvimento inicial de botões foliares e florais, além de diversas outras partes da planta como brotos, folhas, fendas e 
cascas de troncos de árvores, e a esta substância recolhida pelas abelhas é adicionada cera para que a mistura se torne moldável e, durante este processo de retrabalhamento, as abelhas acrescentam secreções de suas glândulas da cabeça, secreções salivares e pólen (Barth et al., 1999; Ministerio de Agricultura, 2001; Vargas et al., 2004; Silva et al., 2006). Segundo Marcucci $(1995,1996)$ o nome própolis é derivado do grego e significa em defesa da cidade neste caso, em defesa da colméia. É um dos muitos produtos naturais utilizados durante séculos pela humanidade, administrada sob diversas formas. Seu emprego já era descrito pelos assírios, gregos, romanos, incas e egípcios. No antigo Egito (1200 A.C., cera negra) eram utilizadas como um dos materiais para embalsamar os mortos e os gregos entre os quais Hipocrates, adotou como cicatrizante interno e externo (Pereira et al., 2002, Castaldo e Capasso, 2002).

Sua utilização de acordo com Arauco et al. (2007a) ocorreu como apiterápico há séculos na medicina popular como agente antiinflamatório e tem atraído a atenção de muitos pesquisadores, principalmente nas últimas duas décadas, no sentido de elucidar suas propriedades biológicas e farmacológicas. De modo geral, contém $50-60 \%$ de resinas e bálsamos, 30-40\% de ceras, 5-10\% de óleos essenciais, $5 \%$ grãos de pólen, além de microelementos como alumínio, cálcio, estrôncio, ferro, cobre, manganês e pequenas quantidades de vitaminas B1, B2, B6, C e E, (Pietta, 2002, Funari e Ferro, 2006, Matsuno, 1995).

A composição da própolis varia de região para região e as substâncias encontradas estão ligadas diretamente ao local de coleta (Wollenweber e Buchmam, 1997). Mais de 200 compostos químicos na própolis, já foram identificados dentre os quais, ácidos fenólicos, flavonóides, ácidos aromáticos, triterpenóides, terpenos ( $\alpha$-esteróides e álcoois), naftaleno, fenóis, aldeídos, álcoois, ácidos alifáticos, ésteres, aminoácidos, esteróides, açúcares, diterpenos, sesquiter- penos e lignanas. O maior grupo é dos flavonóides (flavonas, flavonóis, flavononas) assim como minerais e vitaminas. Além de chalconas, dihidrochalconas, hidrocarbonetos, ácidos graxos, cetonas, terpenóides entre outros (Park et al. 2002(a), 2002(b); El Hady e Hegazi, 2002; Bonvehí e Coll, 1994; Kartal et al., 2002; Aga et al., 1994; Bankova et al., 2002; Marcucci et al., 2000). É conhecida principalmente, por suas propriedades antimicrobianas (Oliveira et al., 2005), antibiótica, antioxidante, imunoestimulante, hepatoprotetora (Banskota et al., 1998, 2000; Borrelli et al., 2002; El-Khatib et al. 2002), antiinflamatória (Dobrowolski, et al., 1991), imunomodulatória, hipotensiva, cicatrizante, anestésica, anti-câncer, antiHIV e anticariogênica (Park et al., 2002a), antifúngica (Murad et al., 2002 ), antiviral (Amoros et al., 1992), antiprotozoaria (Burdock, 1998), anticariogênica (Koo et al., 1999), fotoinibidora (Stangaciu, 1998).

As investigações sobre as propriedades antibióticas da própolis têm sido conduzidas sobre tudo na área médica e veterinária, onde o produto tem demonstrado uma eficiente atividade bacteriostática e bactericida em relação a diversos gêneros de bactérias gram positivas e gram negativas (Bianchini e Bedendo, 1998). Segundo Arauco et al. (2007a), poucos trabalhos têm sido realizados, considerando-se a resposta dos animais frente a algumas dessas atividades biológicas da própolis em termos de índices zootécnicos.

\section{UTILIZAÇÕES DAPRÓPOLISEM ANIMAIS: RUMINANTESENÃO- RUMINANTES}

A própolis está sendo utilizada freqüentemente na área da medicina humana e animal, com obtenção de bons resultados (Park et al., 1995). Trata-se de uma medicina alternativa, chamada de Apiterapia devido às suas várias propriedades terapêuticas e biológicas, em trabalhos científicos do mundo inteiro (Ghisalberti, 1979). Além das 


\section{A PRÓPOLIS E SUA UTILIZAÇÃO EM ANIMAIS DE PRODUÇÃO}

propriedades biológicas mencionadas, a própolis oferece a vantagem de ser um produto natural e sua utilização na área zootécnica pode substituir ou reduzir o uso de quimioterápicos, os quais, na maioria das vezes, são de uso humano, o que acaba encarecendo o produto final, quando se trata de alimentos de origem animal, e principalmente oferecendo riscos á saúde do consumidor. Entretanto sua utilização na área veterinária e zootécnica tem sido limitada pela grande variabilidade nas amostras, devido às fontes vegetais. Além disso, seus componentes de maior ação biológica (flavonóides e ácidos fenólicos) são solúveis em álcool e, tanto este quanto a própolis, podem desencadear quadros de hipersensibilidades e intoxicação em organismos sensíveis (Garcia et al., 2004a).

\section{UTILIZAÇÃO DAPRÓPOLISEM RUMINANTES}

\section{CAPRINOS}

Os principais produtos obtidos da caprino-ovinocultura são carne, pele e leite, que originam diversos derivados após o processamento (Hashimoto et al., 2007).

A exploração de caprinos, voltada para a produção de leite e derivados, apresenta acentuado crescimento no país devido à crescente demanda e à melhor remuneração obtida com os produtos lácteos. Como conseqüência, intensificou-se os sistemas de exploração para alcançar a rentabilidade almejada, o que aumentou, também, os riscos de ocorrência de transtornos metabólicos na cabra, em função de desequilíbrios entre o aporte de nutrientes ao organismo, a capacidade de metabolização desses componentes e o nível de produção alcançado (Mundim et al., 2007). Estudos relatam à possibilidade de modificações no perfil de ácidos graxos do leite de cabra pela suplementação da dieta com fontes lipídicas (óleos, sebos, gorduras) (Fernandes et al., 2008). No período inicial da lactação, a de- manda energética é alta e os animais podem apresentar balanço energético negativo. Sabe-se que cada animal responde a esta situação de forma individual por meio de diferentes mecanismos, como a recuperação da capacidade ingestiva, que, por sua vez, não acompanha a velocidade de produção de leite e a mobilização de gorduras corporais (Rodrigues et al., 2007).

Objetivando avaliar a adição de óleo de soja e/ou extrato etanóico de própolis na alimentação de cabras leiteiras sobre o consumo, a digestibilidade da matéria seca dos nutrientes, composição e produção de leite e parâmetros de fermentação ruminal, Lana et al. (2005a) concluíram que o óleo de soja reduz os consumos de matéria seca e de fibra em detergente neutro na presença de extrato etanólico de própolis, aumentam os teores de gordura, proteína e sólidos totais no leite, e o pH reduz a relação acetato: propionato no líquido ruminal, no entanto interfere pouco no consumo, na digestibilidade, produção e composição do leite e nos parâmetros de fermentação ruminal de cabras em lactação.

Segundo (Teh et al., 1994) na maioria dos experimentos envolvendo suplementação lipídica para ruminantes, são utilizados bovinos como modelo animal, tornando escassas as informações dos efeitos dos lipídios sobre as características de fermentação ruminal em caprinos, além do que caprinos possuem comportamento alimentar e metabolismo diferenciados em relação a outras espécies de ruminantes e, portanto, podem apresentar respostas distintas ao fornecimento de lipídios (Chilliard et al. 2003), com isso Lana et al. (2007b) avaliaram os efeitos da adição de óleo de soja, extrato etanólico de própolis e própolis bruta moída na alimentação de cabras leiteiras sobre o consumo de matéria seca, nutrientes e os parâmetros de fermentação ruminal, concluindo que o uso de própolis e óleo de soja na dieta não afetou o consumo de matéria seca e de nutrientes, nem alterou os parâmetros de fermentação ruminal em 
cabras leiteiras. No entanto os autores sugerem a realização de mais pesquisas com adição de própolis na dieta de animais ruminantes, pois existem evidências de que seu fornecimento a esses animais reduz a relação acetato: propionato e a concentração de butirato no líquido ruminal.

No rúmem a síntese de proteína microbiana atende de 60 a $85 \%$ das exigências para mantença, crescimento, gestação e lactação em ruminantes (Timmermans Jr. et al., 2000). A produção de gases, metano e carbônico, e sua eliminação para o meio, representa perda de energia do ecossistema ruminal proveniente do alimento digerido. Além disso, esses gases eliminados, por eructação, são responsáveis em parte pelo efeito estufa e destruição da camada de ozônio da atmosfera (Chynoweth, 1996). A utilização, portanto, de substâncias que reduzam essa perda de energia na forma de gases é de grande utilidade na alimentação de ruminantes. Neste sentido Stradiotti et al. (2004) avaliaram a ação do extrato de própolis sobre a fermentação in vitro de diferentes alimentos pela técnica de produção de gases objetivando verificar a eficiência da própolis em diminuir a produção de gases de três relações, volumoso: concentrado incubadas in vitro. Os autores concluíram que o extrato de própolis reduziu a produção final de gases para carboidratos fibrosos, e que a taxa de digestão específica para carboidratos fibrosos e carboidratos nãofibrosos foi superior, quando foi utilizado o extrato de própolis estimulando o crescimento microbiano. A redução no volume final de gases foi atribuída, provavelmente, ao fato de a própolis ter possibilitado a conservação de carbono no meio. Essa conservação de carbono no rúmen, em linhas gerais, é decorrência do aumento da concentração molar de propionato (3 carbonos) no rúmen, em detrimento da diminuição da concentração de acetato ( 2 carbonos). Neste sentido, a própolis pode ter atuado como uma substância ionófora, ou seja, a própolis foi eficiente em inibir a produção de gases in vitro pelos microrganismos ruminais, somando-se ao fato de que a mesma possibilitou aumento da taxa de digestão específica dos carboidratos. Segundo Mirzoeva et al. (1997), a própolis e alguns de seus componentes possuem efeitos sobre a permeabilidade da membrana citoplasmática bacteriana aos íons, causando a dissipação do potencial de membrana, o que a caracteriza como substância ionófora.

Estudos têm demonstrado que a própolis atua sobre a inibição de bactérias grampositivas, sendo esperado que sua adição em cultivo de microrganismos ruminais iniba o crescimento de bactérias proteolíticas da mesma forma que o ionóforo monensina (Oliveira et al., 2004). Assim, a monensina é fornecida em dietas para animais que consomem grande quantidade de grãos, em que a economia quanto à aquisição dos alimentos, para os grandes produtores de carne ou leite, se torna importante (Zeoula et al., 2008).

Oliveira et al. (2004) estudaram o efeito da monensina e extrato de própolis sobre a produção de amônia e degradabilidade in vitro da proteína bruta de diferentes fontes de nitrogênio, objetivando avaliar a fermentação da proteína de três fontes de nitrogênio (tripticase, farelo de soja e farinha de peixe), com ou sem a adição dos compostos antimicrobianos monensina e própolis, concluindo que a monensina e a própolis foram ambas eficientes na inibição da produção de amônia nas duas fontes de nitrogênio tripticase e farelo de soja. Entretanto, nas três fontes de nitrogênio, sempre houve maior concentração de proteína solúvel ao início da incubação no tratamento contendo própolis. Este resultado demonstra que a própolis tem forte efeito inibidor da produção de amônia, ou seja, a monensina e a própolis foram eficientes em reduzir a produção de amônia de fontes de proteína de maior degradabilidade. A própolis foi mais eficiente que a monensina em manter maiores concentrações de proteína solúvel no início das incubações, pela redução da 


\section{A PRÓPOLIS E SUA UTILIZAÇÃO EM ANIMAIS DE PRODUÇÃO}

atividade de desaminação.

Dando continuidade em suas pesquisas, Oliveira et al. (2006) estudaram os efeitos in vitro do ionóforo monensina e do extrato de própolis sobre a fermentação ruminal de aminoácidos. Os autores testaram à hipótese de que considerando-se que o extrato de própolis é capaz de extinguir bactérias com alta capacidade de produção de amônia, a atividade de desaminação não retornará aos níveis normais, mesmo após a remoção do extrato do meio de cultura. Entretanto, se o extrato de própolis, como a monensina, causa apenas a inibição do transporte de aminoácidos à membrana, após sua remoção do meio de cultura, por meio de transferências diárias e sucessivas da cultura para meio estéril sem própolis, ocorrerá o aumento da produção de amônia. Findo o experimento, concluíram então que a hipótese testada estava correta, pois a própolis apresenta-se mais eficiente que a monensina em reduzir a produção de amônia de culturas de microrganismos ruminais em meio contendo caseína hidrolisada. A produção de amônia normalizou assim que o ionóforo monensina foi removido do meio de cultura, provavelmente em razão do restabelecimento da população de bactérias produtoras de amônia, comprovando que esse antibiótico apenas inibe estes microrganismos. No entanto os tratamentos com própolis mantiveram, mesmo com sua remoção do meio, baixa produção de amônia e atividade específica de produção de amônia (AEPA), o que justifica a realização de estudos sobre a forma de atuação desse inibidor, que pode ser diferente dos ionóforos nos microrganismos ruminais, eliminando-os realmente ou ter um espectro de ação maior que a monensina, atingindo a população de bactérias Clostridium aminophilum entre outras, de alta capacidade de produção de amônia e mais resistentes à monensina.

\section{Bovinos}

No Brasil, a produção de leite, como em outros segmentos da atual sociedade, é uma atividade cada vez mais competitiva. Portanto, é importante quantificar e qualificar os fatores que podem influenciála, buscando ganhos efetivos na quantidade e qualidade do leite produzido, na tentativa de suprir a demanda nacional (Coldebella et al. 2004). A mastite éum processo inflamatório da glândula mamária acompanhado da redução de secreção de leite e mudança de permeabilidade da membrana que separa o leite do sangue (Pereira et al. 2001). Essa doença é a de maior relevância na bovinocultura e é associada às infecções microbianas (Paes et al. 2003). Recentemente os microrganismos envolvidos na gênese da mastite bovina foram convencionalmente agrupados de acordo com as fontes de infecção e vias de transmissão, e classificados como contagiosos ou ambientais (Costa, 1998). Com relação ao perfil microbiológico dos rebanhos, vários trabalhos têm apontado que o Staphylococcus sp é o principal agente causador de mastite no Brasil (Laranja e Machado, 1994, Cardoso et al. 2000). A presença de $S$. aureus e suas toxinas no leite usado pelas indústrias nos laticínios representam sério problema de saúde pública (Ichikawa et al., 1996).

De acordo com Langoni et al. (2000) diversos estudos que tratam da susceptibilidade a antimicrobianos de patógenos da mastite bovina no Brasil mostram aumento crescente no padrão de resistência, principalmente para Staphylococcus aureus, o agente mais freqüentemente isolado. O tratamento precoce desta afecção aliado as outras medidas constitui importante profilaxia, pois elimina uma fonte de infecção em potencial para as demais vacas lactantes, nesse tratamento pode-se lançar mão de vários medicamentos, entretanto, muitas vezes pode ocorrer o insucesso terapêutico, tendo em vista a possível seleção de microrganismos resistentes, sendo a resistência microbiana o principal motivo da ineficiência terapêutica na mastite. Na literatura científica existem poucos trabalhos sobre o uso de extratos de própolis e/ou derivados no tratamento ou 
prevenção da mastite bovina ou de outras espécies domésticas (Pinto et al., 2001).

Segundo Takaisi-Kikuni e Schilcher (1994), o extrato etanólico de própolis inibe o crescimento bacteriano por prevenir a divisão celular e por produzir defeitos na estrutura da parede celular, levando à bacteriólise parcial e à formação de bactérias pseudomulticelulares (policarióticos) e, ainda, desorganiza o citoplasma, caracterizado pela presença de espaços vazios ou estruturas fibrosas, além de causar alteração na membrana citoplasmática e inibir a síntese protéica. Meresta et al. (1989) estudou o tratamento de mastite com extrato de própolis e obtiveram recuperação completa em $86,6 \%$ das vacas com mastite aguda e de $100 \%$ nos casos de infecção causada por Candida albicans, 85\% por Escherichia coli, 91\% por Staphylococcus sp. e de $84,3 \%$ por Streptococcus sp. mostrando que a própolis apresentou-se bastante eficaz na terapia de mastite causada por microrganismos resistentes aos antimicrobianos convencionais. Langoni et al. (1996) estudaram o efeito antimicrobiano in vitro da própolis, e obtiveram 90\% de inibição ao Streptococcus agalactiae e $100 \%$ ao Staphylococcus aureus. Na mesma vertente, Pinto et al. (2001) estudou o efeito de extratos de própolis verde sobre bactérias patogênicas isoladas do leite de vacas com mastite e concluíram que, as amostras de própolis estudadas exerceram efeito antibacteriano através dos extratos etanólico e, em menor proporção, do metanólico, sobre o Staphylococcus aureus, Staphylococcus sp. coagulase negativos, e Streptococcus agalactiae, mas não mostrou capacidade em inibir o crescimento das amostras gramnegativas, nas concentrações utilizadas, ou seja a espécie gram-negativa avaliada não apresentou sensibilidade a nenhum dos extratos, não evidenciando halo de inibição. Porém, amostras diferentes, de uma mesma espécie bacteriana, diferiram quanto à sensibilidade à própolis.

Loguercio et al. (2006), objetivando avaliar a atividade in vitro de extrato de própolis e de antimicrobianos, comumente utilizados contra os agentes bacterianos da mastite bovina, concluíram que entre as 63 amostras bacterianas testadas, 57 (90,5\%) apresentaram sensibilidade ao extrato de própolis. A sensibilidade média dos isolados de Staphylococcus coagulase-positivos $(94,4 \%)$ foi superior à dos isolados de Streptococcus sp. (85,2\%), e nos testes com isolados do gênero Staphylococcus, observou-se maior porcentual de linhagens sensíveis ao extrato de própolis e sulfazotrim $(94,44 \%)$. Na análise dos resultados de isolados do gênero Streptococcus, foi observado que o extrato de própolis, inibiu o crescimento de $85,18 \%$ dos isolados, com isso observaram que o extrato de própolis possuiu efeito antimicrobiano sobre Staphylococcus coagulase-positivo e Streptococcus sp., isolados de casos de mastite bovina, demonstrando percentuais de atuação superiores ou semelhantes aos de antimicrobianos comumente utilizados na terapia dessa enfermidade, no entanto por se tratar de estudo in vitro, outros aspectos precisam ser pesquisados com o objetivo da utilização in vivo da própolis.

\section{UTILIZAÇÃO DA PRÓPOLIS EM NÃO- RUMINANTES}

\section{Aves}

A avicultura é a atividade que possui o maior e mais avançado acervo tecnológico dentre o setor agropecuário brasileiro. Os grandes progressos em genética, nutrição, manejo e sanidade verificados nas últimas quatro décadas transformaram o empreendimento num verdadeiro complexo econômico, traduzido por uma grande indústria de produção de proteína de origem animal (Tinoco, 2001).

Segundo Furtado et al. (2005) a avicultura tem passado por constantes inovações com o objetivo de melhorar o rendimento do processo produtivo. No entanto essa gran- 


\section{A PRÓPOLIS E SUA UTILIZAÇÃO EM ANIMAIS DE PRODUÇÃO}

de expansão exigiu a utilização de antibióticos promotores de crescimento que têm por finalidade controlar os agentes prejudiciais ao trato digestivo e proporcionar os efeitos benéficos na absorção de nutrientes (Vassalo et al., 1997), porém, há consenso em vários países que o uso indiscriminado de antibióticos na produção animal é uma das causas do aumento da resistência antimicrobiana. $\mathrm{O}$ uso de antimicrobianos pode selecionar bactérias resistentes no ecossistema, tornando-se patógenos para humanos além de genes resistentes podem passar entre humanos, animais e outros ecossistemas, via contato com animais ou através do consumo de alimento ou água contaminada (Kelley et al., 1998). As alternativas mais pesquisadas envolvem o uso de enzimas, probióticos, prebióticos, ácidos orgânicos e extratos vegetais, e é nessa última categoria que a própolis se destaca, já que possui inúmeras características de interesse. O extrato de própolis é uma alternativa não-convencional para controlar processos infecciosos, no entanto, estudos sobre os benefícios nutricionais da própolis ainda são escassos.

De acordo com Biavatti et al. (2003) a utilização da própolis foi eficaz em frangos, apresentando melhores desempenhos a partir de 14 a 21 dias de idade. Os resultados do estudo sugerem que o extrato de própolis pode ser usado como agente antimicrobiano, uma vez que eles melhoraram o desempenho das aves, porém se faz necessário mais estudos para encontrar uma adequada concentração a ser adicionada na dieta. Tais resultados se devem ao efeito antimicrobiano resultar em melhor saúde e melhora na digestão intestinal e absorção de nutrientes. Neste sentido Franco et al. (2007) estudando índices produtivos e rendimento de carcaça de frangos de corte alimentados com dietas contendo níveis de extrato etanólico de própolis e promotores de crescimento convencionais objetivando avaliar a eficiência do extrato de própolis como substituto aos antibióticos conven- cionais e determinar os efeitos dos diferentes níveis de extrato etanólico de própolis sobre o desempenho de frangos de corte de 1 a 42 dias de idade, encontraram que o desempenho e o rendimento de carcaça de frangos de corte alimentados com dietas contendo extrato etanólico de própolis foram similares aos das aves do tratamento sem promotor de crescimento. No entanto, é preciso ressaltar que o objetivo primário de sua utilização é substituir os antibióticos promotores de crescimento, ou seja, proporcionar desempenho similar ao dos antibióticos.

O surgimento de uma população microbiana no trato gastrintestinal de todos os animais, logo após o nascimento é inevitável. Conseqüentemente, os antibióticos diferem no que diz respeito a sua habilidade em influenciar determinados estados da doença ou melhorar o crescimento e/ou a eficiência alimentar (Miles et al., 2006). Na ausência de bactérias gastrintestinais, devido à presença de antibióticos na dieta, a necessidade do recrutamento de células imunes para o intestino ficam reduzidas e conseqüentemente, o desempenho animal não é melhorado caso não ocorra o equilíbrio da microbiota intestinal, assim patógenos no intestino causar lesões no vilo, resultando em infecção intestinal, o que pode comprometer a digestibilidade da ração e ocasionalmente o surgimento de doenças. Dentre as principais doenças que acometem as aves, a salmonela trata-se de um gênero bacteriano dos mais estudados microbiologicamente. São microrganismos capazes de provocar enfermidades em seres humanos e animais. Salmonelose aviária designa doenças agudas ou crônicas, causadas por um ou mais membros do gênero Salmonella (Hogue et al., 1997).

Para Mazzuco et al. (1996) o controle da infecção das aves por salmonelas paratíficas tem por finalidade evitar a possibilidade do desenvolvimento da enfermidade nas aves, bem como impedir a toxinfecção alimentar em seres humanos por salmonelas devido à 
ingestão de produtos alimentares de origem avícola infectados. As medidas gerais de profilaxia dificultam, mas não impedem a presença de bactérias nas granjas e nenhuma das tentativas de eliminação têm sido eficientes em erradicar de fato a bactéria do meio avícola. E, com essa preocupação, os autores estudaram a utilização da própolis e álcool etílico no controle de Salmonella em rações avícolas, com o objetivo de investigar a ação da própolis e do álcool etílico em rações desafiadas com diferentes sorotipos de Salmonella, fornecidas a pintos de corte de um dia e encontraram nos tratamentos com a própolis em solução alcoólica e tratamento com álcool etílico a eliminação de S. typhimurium e S.enteritidis da ração.

Cizmarik e Matel (1973) demonstraram também a atividade da própolis contra Staphilococcus aureus, C.difhterie e $P$.vulgaris em aves.

Buhatel et al. (1983) utilizando uma emulsão alcoólica de própolis em rações de frangos de corte atestaram a melhora do ganho de peso diário das aves em 41 e 18\% respectivamente, quando comparado aos animais que não receberam própolis, esses autores concluíram ainda que a própolis preveniu desordens digestivas e proporcionou melhor conversão alimentar. Utilizando extrato alcoólicos de própolis testados in vitro, Valdes et al. (1989), observaram que o extrato apresentou efeito antibiótico que foi notado sobre bactérias gram-negativas como a Salmonella.

Orsi et al. (2005) comparou a atividade antibacteriana do extrato etanólico de própolis produzido em duas diferentes regiões do Brasil contra a Salmonella enteritidis (isoladas de alimentos) e Salmonella typhimurium (isoladas de infecções humanas) e verificou que a própolis apresentou atividade bactericida contra Salmonella enteritidis e Salmonella typhimurium mostrando um notável efeito inibitório após 14 horas e efeito bactericida após 24 horas. No entanto a bactéria só foi inibida pela própolis com a concentração mais elevada (10,0\%), mostrando que a ação da própolis é limitada em bactérias gramnegativas, porém é possível sua utilização como uma alternativa de controle de infecção por salmonelas. Também ficou evidente que a amostra de própolis do Nordeste do Brasil (Mossoró - RN), foi mais eficaz contra a Salmonella do que a do Sul (Urubici, SC), embora ambas as amostras tenham demonstrado atividade bactericida. Sugerindo-se então que outros estudos com compostos isolados seriam importantes para melhor compreensão deste produto e suas propriedades biológicas, pois a atividade antibacteriana da própolis contra as bactérias gram-negativas podem variar de acordo com a região geográfica onde a própolis foi produzido.

Domesmomodo, Orsi(2007), objetivando investigar a susceptibilidade de cepas de Salmonella, isoladas de processos infecciosos e de alimentos, para a ação antibacteriana da própolis brasileira e búlgara, bem como determinar o comportamento dessas bactérias, de acordo com o período de incubação, acrescidas de própolis, constatouse que as duas amostras da própolis mostraram uma ação antibacteriana contra todas as cepas de Salmonella, porém as concentrações inibitórias mínimas de própolis foram semelhantes, apesar de terem sido coletadas em diferentes regiões geográficas. As cepas de Salmonella enteritidis (isoladas do alimento) foram mais suscetível a própolis brasileira e búlgara em comparação com as cepas de Salmonella typhimurium, isoladas das infecções humanas apresentando maior resistências às duas amostras de própolis.

\section{SuÍNOS}

A suinocultura moderna tem como finalidade atender à demanda dos consumidores por produtos cárneos de qualidade e com segurança alimentar, aumentando a quantidade de carne produzida por matriz e, ao mesmo tempo, reduzindo os custos de produção(Silva et al., 2008). Com a finalidade 
de aumentar a produtividade das porcas, a maioria das granjas tecnificadas desmama os leitões com idade média de 21 dias (Robert et al., 1999, Giroux et al., 2000). O período pós-desmame é a fase mais crítica no desenvolvimento dos suínos, principalmente porque neste período o sistema digestório está pouco adaptado para o aproveitamento de alimentos sólidos, diferentes do leite (Scandolera et al., 2008). Para compensar a imaturidade digestiva dos leitões, são utilizados antibióticos como promotores de crescimento, para suínos, pois especula-se que os antimicrobianos possam eliminar ou controlar microrganismos que causam queda no desempenho animal (Pedroso et al., 2005). Apesar da comprovada capacidade de melhorar o desempenho de suínos, o uso de antimicrobianos como promotores de crescimento tem sido progressivamente restringido em diversos países, o que estimula a busca por alternativas como a utilização de extratos vegetais (Oetting et al., 2006).

Em condições brasileiras, são poucas as pesquisas que comprovam a ação dos extratos vegetais como promotores de crescimento de suínos. Os resultados são bastante controversos e pouco conclusivos (Costa et al., 2007). Nesta classe de substâncias de extratos vegetais se enquadra à própolis que vem despertando interesse na sociedade por apresentar propriedades biológicas, com efeito antibactériano, antiviral, antiinfeccioso, antiinflamatório, antifúngico, antitumoral, imunoestimulante, agente antioxidante entre outros. As diversas propriedades fármaco-terapêuticas, fazem com que a própolis se encaixe como elemento importante na aceitação por grande parte da população mundial. Neste sentido Buhatel et al. (1983) afirmaram que a utilização de emulsão alcoólica de própolis em rações de leitões melhorou o ganho de peso diário em 41 e $18 \%$ respectivamente, quando comparado aos animais que não receberam própolis, esses autores concluíram ainda que a própolis preveniu desordens digestivas e proporcionou melhor conversão alimentar nestes animais. Sanchez e Galardi (1989) testaram à aplicação oral da emulsão aquosa de própolis (10\%) em 60 leitões desmamados (Yorkshire-Duroc), e observaram que os animais tratados tiveram maior ganho de peso, resultado de uma ação estimulante da própolis sobre o apetite dos animais, ou seja, existe em leitões, uma ação positiva de emulsão aquosa (10\%) de própolis ministrada oralmente. A melhora observada no desempenho dos animais pode ser conseqüência de uma melhora na resposta imunológica dos mesmos após o consumo de própolis. Em situações estressantes, a microbiota intestinal sofre alterações e as populações de bactérias benéficas diminuem, por sua vez, aumentam às patogênicas que geram metabólitos tóxicos ao hospedeiro, causando inflamações na mucosa intestinal, além de estabelecer condições propícias ao surgimento de enfermidades, e estas alterações provocam prejuízos imediatos no desempenho animal (Silva e Nörnberg, 2003).

Por outro lado Dierckx e Funari (1999), estudando o uso da própolis na alimentação de leitões desmamados como aditivo e na prevenção à diarréia não observaram diferenças significativas para ganho de peso, consumo de ração e conversão alimentar em leitões que receberam rações com diferentes níveis de extrato alcoólico de própolis $(0,05 \%, 0,15 \%$ e $0,45 \%)$, o experimento avaliou um tratamento sem própolis, um sem coccidiostático, um com promotor de crescimento (controle negativo), um tratamento com própolis e um sem os outros dois aditivos (controle positivo), os autores observaram tendência de pior desempenho produtivo dos animais no grupo controle negativo, como também que as rações com própolis não diferiram daquela sem nenhum tipo de tratamento, nem da com promotor de crescimento e coccidiostático para ganho de peso, consumo de ração e conversão alimentar.

\section{RÃ-TOURO}

A ranicultura tem se tornado uma im- 
portante atividade econômica em muitos países (Rodríguez-Serna et al., 1996), além de ser uma atividade que vem se consolidando, graças ao avanço da tecnologia, oferece possibilidade de retorno econômico aos produtores, em virtude do elevado preço da carne de rã-touro (Rana catesbeiana) e de sua excelente qualidade nutricional (Lima e Agostinho, 1992). A criação de rã, no entanto apresentam altas taxas de mortalidade principalmente, no final da metamorfose, decorrente de desnutrição, estresse, instalações e manejo inadequados.

As doenças nas espécies criadas em cativeiros, principalmente as de origem infeccciosa, têm considerável importância, pois limitam o potencial reprodutivo das rãs e a rentabilidade comercial das empresas que exploram o ramo (Souza et al., 1993). As bacterioses são as causas da maioria das mortes em populações de rãs, causando prejuízos para os criadores.

Poucos são os trabalhos que utilizam própolis em animais aquáticos, neste intuito Arauco et al. (2007a), objetivando avaliar o efeito de diferentes concentrações do extrato hidroalcoólico de própolis no desempenho (ganho de peso, consumo de ração, comprimento, conversão alimentar, tempo de metamorfose e sobrevivência) e na composição leucocitária do sangue de girinos de rã-touro (Rana catesbeiana), concluíram que a adição de extrato hidroalcoólico de própolis na ração melhorou o ganho de peso de girinos de rã-touro e influenciou a porcentagem de monócitos no sangue periférico, apresentando possivelmente efeito imunoestimulante nas doses mais baixas (0,2 e 0,5\%). A mudança na composição leucocitária observada nos animais pode ser conseqüência de uma melhora na resposta imunológica dos mesmos após o consumo de própolis demonstrando assim a função e atuação da própolis.

Dando continuidade em suas pesquisas, os mesmos autores Arauco et al. (2007b), verificaram a ocorrência de possíveis alterações histológicas no rim, fígado e intestino, bem como na espessura do epitélio intestinal de girinos de rãtouro submetidos a dietas com diferentes concentrações de extrato hidroalcoólico de própolis $(0,2,05,1,0$ e 1,5). Concluíram que mediante microscopia de luz não se observaram alterações celulares do epitélio dos rins, fígado e intestino, nem mudanças na espessura do epitélio do intestino de girinos de rã-touro submetidos a diferentes concentrações de extrato hidroalcoólico de própolis, ou seja, macroscopicamente o fígado apresentou-se aparentemente normal, com coloração marrom avermelhada e consistência firme não se verificando lesões celulares nos hepatócitos causada pelo consumo de extrato hidroalcoólico de própolis na ração. A espessura do epitélio intestinal dos girinos não foi influenciada pelas diferentes concentrações de própolis testadas. Atestando dessa forma que a própolis nem causou sintomas clínicos de intoxicação, que podem ser provocadas por substâncias químicas e drogas, as quais são importantes causas de adaptações, lesão e morte celular, nem anormalidades histológicas no fígado, ou seja, apresentou efeito hepato protetor confirmando a importância deste para a conservação das biomembrana do fígado, rim e intestino.

\section{Coelhos}

A demanda de carne de coelhos é crescente por ser uma alternativa saudável à alimentação do homem. Dentre suas qualidades dietéticas destacam-se: a cor branca, a proteína de alto valor biológico e, sobretudo, o baixo teor de gordura predominante nos ácidos graxos insaturados (Russo etal., 1998).

O fato do coelho possuir aparelho digestivo desenvolvido, principalmente o ceco, com ativa ação microbiana, resulta em uma alta capacidade de aproveitamento de nutrientes quando comparado a suínos e aves (Ferreira et al., 1997), por outro lado a microbiota do trato digestivo possui uma 


\section{A PRÓPOLIS E SUA UTILIZAÇÃO EM ANIMAIS DE PRODUÇÃO}

ação significativa no estado sanitário dos animais e nos parâmetros zootécnicos dos mesmos relacionados aos microorganismos.

Por suas propriedades biológicas, a própolis surge como alternativa no combate a estes microorganismos oferecendo vantagens por ser um produto natural e de baixo custo quando comparada a quimioterápicos, que na maioria das vezes, são de uso humano, oferecendo riscos à saúde do consumidor ao comprar produtos de origem animal, podendo substituir ou reduzir o uso destes medicamentos que na área zootécnica encarecem o produto final (Garcia et al., 2004a).

No intuito de testar a atividade da própolis como vermífugo Hollands et al. (1984) em diferentes pesquisas sobre coccidiose em coelhos, provocada por protozoários do gênero Eimeria, administraram extrato alcoólico de própolis a $2 \%$ ou $3 \%$, via oral, na água. No primeiro experimento, utilizaram o extrato em 18 coelhos, por 15 dias e observaram uma redução significativa da intensidade da doença, medida pela presença de oocistos nas fezes dos animais tratados, observando que o extrato a 3\% foi mais efetivo nessa redução em relação àquela observada nos animais do grupo controle (álcool a 95º. No segundo experimento, Hollands et al. (1988) utilizou 12 animais, os autores compararam a própolis a $3 \%$ e sulfonamidas (sulfametazina e sulfaquinoxalina) a $0,1 \%$ e $0,2 \%$, habitualmente utilizadas como coccidiostáticos em coelhos, para os animais que receberam a própolis e as sulfonamidas foi observada redução expressiva na intensidade da coccidiose, não sendo observada redução no grupo controle. Em uma terceira pesquisa Hollands et al. (1989) os mesmos autores acompanharam a mortalidade e a incidência de diarréia em 80 coelhos, 40 tratados com própolis e 40 no grupo controle (álcool a $95^{\circ}$ ), foi verificado um período de recuperação duas vezes maior dos animais tratados com a própolis quando comparados ao grupo controle, observando mortalidades de 10 e $30 \%$ respectivamente. Diante dos resultados obtidos, os autores concluíram que a própolis pode ser utilizada para combater a coccidiose por sua eficiência e economia, propiciando aumento da produtividade pela redução na mortalidade.

Oliveira et al. (2005) objetivando pesquisar se a dose de $150 \mathrm{mg} / \mathrm{kg} /$ dia de extrato bruto de própolis ocasiona algum efeito adverso nos níveis séricos e nas enzimas aspartato aminotransferase, alanina aminotransferase e gama glutamiltranspeptidase de coelhos adultos, observaram que a própolis não ocasionou alterações significativas na atividade da aspartato aminotransferase (AST), levando a crer que também não causaram danos relacionados ao aumento da atividade dessa enzima nos animais utilizados, não sendo observada hepatotoxicidade quando da utilização do extrato bruto de própolis.

Em estudos realizados por Moura et al. (1998) avaliando o efeito da solução hidroalcoólica de própolis e robenidina sobre a contagem de oocistos por grama de fezes de Eimeria spp. em coelhos da raça Nova Zelândia Branco, sob o efeito do fornecimento de própolis nas doses $0,4,8$, 12 e $16 \mathrm{ml}$ de solução hidroalcoólica de própolis/litro de água, como coccidiostático, ofertados dos 40 aos 90 dias de idade, comparando com a robenidina $(0,1 \%$ na ração e água pura). Verificaram que o último tratamento foi mais eficiente como coccidiostático que o primeiro, embora o aumento na concentração da solução hidroalcoólica de própolis, adicionada à água de beber, tenha reduzido linearmente o número de oocitos de Eimeria spp. por grama de fezes. Garcia et al. (2004b) em estudos para verificar a atividade in vitro da própolis sobre a Pasteurella multocida, bactéria gram negativa, bem como observar o efeito do extrato alcoólico de própolis adicionado à ração, sobre bactérias do mesmo gênero e espécie, em coelhos adultos da raça Norfolk 2000, encontraram que a própolis demonstrou ação contra a Pasteurella multocida in vitro, 
e atuou também sobre essa bactéria nos coelhos, quando fornecida incorporada às rações, tendendo a reduzir o número de unidades formadoras de colônias dessa bactéria gram negativa, em nível tráqueobrônquico dos animais. Dessa forma, nas condições testadas, a própolis mostrou-se favorável como auxiliar no controle da Pasteurella multocida nos coelhos, uma vez que, principalmente em situações de estresse dos animais, os sintomas respiratórios, reprodutivos e neurológicos provocados por essa doença têm causado prejuízos em algumas criações.

Os índices zootécnicos com própolis também foram testados por Garcia et al. (2004a) no estudo do efeito de níveis de extrato seco de própolis sobre o perfil bioquímico e o desempenho de coelhas jovens, avaliando o perfil bioquímico sérico, como forma de detectar alguma possível ação tóxica da mesma, bem como o acompanhamento do desempenho corporal dos animais, após o fornecimento de rações contendo diferentes quantidades de própolis. Os autores concluíram que a adição de própolis em pequenas quantidades à ração $(0,1 \%$ de extrato seco de própolis) demonstrou-se efetiva sobre o desempenho dos animais, tendo melhorado o ganho de peso dos mesmos e sua conversão alimentar. Em níveis mais elevados (0,3\% de extrato seco de própolis), a adição apresentou influência negativa sobre o desempenho, embora não tenha provocado alterações bioquímicas séricas importantes que pudessem indicar reações adversas à sua administração.

Ao avaliarem o desempenho de coelhos em crescimento, que receberam solução hidroalcoólica de própolis (SHP) e robenidina (coccidiostático), Scapinello et al. (1998), concluíram que a inclusão de SHP prejudicou o desempenho dos coelhos, tanto no período de 40 a 70 dias de idade, como no total do experimento de 40 a 90 dias de idade. Já a utilização da robenidina, quando comparada a SHP, permitiu um melhor desempenho dos animais. Entretanto o fornecimento da
SHP foi na água e a robenidina na ração. Além das diferenças nos fornecimentos dos tratamentos, os níveis de extrato resinoso na água foram muito baixos, já que a solução hidroalcoólica de própolis ainda foi adicionada à água, e a robenidina, que é o princípio ativo, foi acrescentada em maiores quantidades à ração. A quantidade de álcool do tratamento placebo $(2,2 \mathrm{ml} / \mathrm{l}$ de água, ou seja, 0,22\%) também foi bem superior em relação ao tratamento que conteve o maior nível de SHP $(0,064 \%)$, fator que pode ter interferido no consumo da ração, pois o álcool pode ter funcionado como estimulante do apetite, superestimando os resultados observados (maiores nos animais desse grupo).

Utilizando extrato etanólico de própolis sobre o ganho de peso, parâmetros de carcaça epH cecal, de coelhos em crescimento, Coloni et al. (2007) indicam que a adição do extrato etanólico de própolis e do álcool etílico, neste experimento, não modificou o $\mathrm{pH}$ do conteúdo cecal. Portanto este órgão, que é parte constituinte do aparelho gástrico, fundamental na digestão de alimentos fibrosos, não sofreu ação das doses quanto ao $\mathrm{pH}$, as quais poderiam interferir nos processos fermentativos cecais e, conseqüentemente, no crescimento dos coelhos. Possivelmente, as boas condições sanitárias e ambientais durante a condução do experimento tenham sido a causa da falta de resposta, em relação ao uso da própolis, sobre a melhoria dos parâmetros aqui estudados. Este estudo seria mais conclusivo se, após iniciar o fornecimento do extrato aos coelhos, todos os animais fossem submetidos a desafios com os principais agentes patogênicos que parasitam o ceco na fase de terminação, causando mortalidade e baixo rendimento, permitindo, assim, verificar a ação antiprotozoária, antimicrobiana, antifúngica e antibiótica da própolis. A adição de extrato etanólico de própolis resultou em ganho de peso, parâmetros de carcaça e $\mathrm{pH}$ cecal dos coelhos semelhantes aos que receberam as dietas com o álcool etílico e sem nenhum 


\section{A PRÓPOLIS E SUA UTILIZAÇÃO EM ANIMAIS DE PRODUÇÃO}

aditivo. Entretanto os coelhos que receberam o extrato etanólico de Própolis apresentaram maiores pesos das patas e os que nenhum aditivo receberam apresentaram maiores pesos do aparelho gástrico.

\section{CONSIDERAÇÕESFINAIS}

Os estudos apresentados nesta revisão mostraram a importância e a eficiência da utilização da própolis na produção animal com uma alternativa não-convencional, apresentando propriedades fármacoterapêuticas, melhorando a resposta imunológica dos animais e os índices zootécnicos.

Em ruminantes os estudos mostraram que a própolis atua principalmente na redução da relação acetato: propionato no liquido ruminal, na redução do crescimento

\section{BIBLIOGRAFIA}

Aga, H., Shibuya, T., Sugimoto, T., Kurimoto, M., Nakajima, S. 1994. Isolation and identification of antimicrobial compounds in Brazilian propolis. Biosci., Biotechnol. Biochem., 58: 945-946.

Amoros, M., Sauvager, F., Girre, L. and Gormier, M. 1992. In vitro antiviral activity of propolis. Apidologie, 23: 231.

Arauco, L.R.R., DE Stéfani, M.V. e Nakaghi, L.S.O. 2007a. Efeito do extrato hidroalcoólico de própolis no desempenho e na composição leucocitária do sangue de girinos de rã-touro (Rana catesbeiana). Acta Sci. Anim. Sci., 29: 227-234.

Arauco, L.R.R., De Stéfani, M.V., Nakaghi, L.S.O. e Oliveira-Bahia, V.R.L. 2007b. Histologia do rim, fígado e intestino de girinos de rã-touro (Rana catesbeiana) alimentados com dietas contendo própolis. Cienc. Rural., 37: 1436-1441.

Bankova, V., Popova, M., Bogdanov, S. and Sabatini, AG. 2002. Chemical composition of European propolis: ex-pected and unexpected results. $Z$. Naturforsch., 57: 530-533.

Banskota, A.H., Tezuka, Y., Prasain, J. K., Matsushige, K., Saiki, I. and Kadota, S. 1998. Chemical constituents of Brazilian propolis and microbiano, atuando como substância ionófora, ou seja, atuando na permeabilidade da membrana citoplasmática bacteriana causando a dissipação do potencial de membrana. Atua também inibindo o crescimento bacteriano principalmente bactérias grampositivas e algumas cepas de bactérias gramnegativas evitando doenças importantes que atrapalham a produtividade.

Em não-ruminantes a própolis atua principalmente no controle de processos infecciosos, consequentemente melhorando a resposta imunológica, o desempenho, as desordens digestivas e a conversão alimentar. A própolis surge como alternativa por ser um produto natural e de baixo custo, no entanto grande parte dos estudos foram in vitro, sendo necessário maiores estudos in vivo, além de uma padronização das dosagens dos extratos.

their cytotoxic activities. J. Nat. Prod., 61: 896900.

Barth, O.M. Dutra, V.M.L. e Justo, R.L. 1999. Análise polínica de algumas amostras de própolis do Brasil meridional. Cienc. Rural, 29: 663-667.

Bianchini, L. e Bedendo, I.P. 1998. Efeito antibiótico da própolis sobre bactérias fitopatogênicas. Sci. Agr., 55: 149-152.

Biavatti, M.W., Bellaver, M.H., Volpato, L., Costa, C. and Bellaver, C. 2003. Preliminary studies of alternative feed additives for broilers: Alternanthera brasiliana extract, propolis extract and linseed oil. Rev. Bras. Cienc. Avic., 5: 147151.

Bonvehí, J.S. and Coll, F.V. 1994. Phenolic composition of propolis from China and South America. Z. Naturforsch., 49: 712-718.

Borrelli, F., Maffia, P., Pinto, L., Lanaro, A., Russo, A., Capasso, F. and Ialenti, A. 2002. Phytochemical compounds involved in the antiinflammatory effect of propolis extract. Fitoterapia, 73: S53-S63.

Buhatel, T., Vesa, S., Dimitrin, A. e Moldovan, I. 1983. Contributii la cunoasterca actiunii 


\section{COELHO, SILVA, OLIVEIRA, AMÂNCIO, SILVAE LIMA}

biostimulatoare a propolisului asupra tincretului porcin si aviar. Bul. Inst. Agron., 37: 45-48.

Burdock, G.A. 1998. Review of the biological properties and toxicity of bee propolis (propolis). Food Chem. Toxicol., 36: 347-363.

Cardoso, H.F.T., Carmo, L.S. e Silva, N. 2000 Detecção da toxina-1 da síndrome do choque tóxico em amostras de Staphylococcus aureus isoladas de mastite bovina. Arq. Bras. Med. Vet. Zootec., 52: 07-10.

Castaldo, S. and, Capasso, F. 2002. Propolis, an old remedy used in modern medicine. Fitoterapia, 73: S1-S6

Chilliard, Y., Ferlay, A., Rouel, J., Lamberet, G. 2003. A review of nutritional and physiological factors affecting goat milk lipid synthesis and lipolysis. J. Dairy Sci., 86: 1751-1770.

Chynoweth, D.P. 1996. Environmental impact of biomethanogenesis. Environ. Monit. Asses. 42: 3-18.

Cizmárik, J. and Matel, I. 1973. Examination of the chemical composition of propolis. 2. Isolation and identification of 4-hydroxy-3-Methoxycinnamic acid (ferulic acid) from propolis. $J$. Apic. Res., 12: 52-4.

Coldebella, A., Machado, P.F., Demetrio, C.G.B. Ribeiro Júnior, P.J., Meyer, P.M., Corassin, C.H. e Cassoli, L.D. 2004. Contagem de células somáticas e produção de leite em vacas holandesas confinadas. Rev. Bras. Zootecn., 33: 623-634.

Coloni, R.D., Lui, J.F., Santos, E., Cavalcante Neto, A., Zanato, J.A.F., Silva, L.P.G. e Malheiros, E.B. 2007. Extrato etanólico de própolis sobre o ganho de peso, parâmetros de carcaça e pH cecal de coelhos em crescimento. Biotemas, 20: 59-64.

Costa, E.O. 1998. Importância da mastite na produção leiteira do país. Rev. Educ. Cont., 1: 3-9.

Costa, L.B., Tse, M.L.P. e Miyada, V.S. 2007. Extratos vegetais como alternativas aos antimicrobianos promotores de crescimento para leitões recém-desmamados. Rev. Bras. Zootecn., 36: 589-595.

Dierckx, S.M.A.G. e Funari, S.R.C. 1999. Uso da própolis na alimentação de leitões desmamados como aditivo e na prevenção à diarréia. Arch. Latinoam. Prod. Anim., 7: 109-116.

Dobrowolski, J.W., Vohora, S.B., Sharma, K.,
Shah, S.A., Naqvi, S.A.H. and Dandiya, P.C. 1991. Antibacterial, antifungal, antiamoebic, antiinflammatory and antipyretic studies on própolis bee products. J. Etnopharmacol., 35: 77.

El Hady, A.F.K. and Hegazi, A.G. 2002. Egyptian propolis 2. Chemical composition, antiviral and antimicrobial activities of East Nile Delta propolis. Z. Naturforsch., 57: 386-394.

El-Khatib, A.S., Agha, A.M., Mahran, L.G. and Khayyal, M.T. 2002. Prophylactic effect of aqueous propolis extract against acute experimental hepatotoxicity in vivo. $Z$. Naturforsch., 57: 379-385.

Fernandes, M.F., Queiroga, R.C.R.E., Medeiros, A.N., Costa, R.G., Bomfim, M.A.D. e Braga, A.A. 2008. Características físico-químicas e perfil lipídico do leite de cabras mestiças Moxotó alimentadas com dietas suplementadas com óleo de semente de algodão ou de girassol. Rev. Bras. Zootecn., 37: 703-710.

Ferreira, W.M., Sartori, A.L., Santiago, G.S. e Veloso, J.A.F. 1997. Digestibilidade aparente dos fenos de rami (Boehmeria nivea, G.), guandu (Cajanus cajan, L.), soja perene (Glycine wightii, V.) e da palha de feijão (Phaseolus vulgaris, L) em coelhos na fase de crescimento. Arq. Bras. Med. Vet. Zootec., 49: 465-472.

Franco, S.S., Rosa, P., Lengler, S., Uttpatel, R., Zanella, I., Gressler, C. e Souza, H.M. 2007. Índices produtivos e rendimento de carcaça de frangos de corte alimentados com dietas contendo níveis de extrato etanólico de própolis ou promotores de crescimento convencionais. Cienc. Rural, 37: 1765-1771.

Funari, C.S. e Ferro, V.O. 2006. Análise de própolis. Cienc. Tecnol. Aliment., 26: 171-178.

Furtado, D.A., Tinoco, I.F.F., Nascimento, J.W.B., Leal, A.F. e Azevedo, M.A. 2005. Caracterização das instalações avícolas na mesorregião do Agreste Paraibano. Eng. Agríc., 25: 831-840.

Garcia, R.C., Pinheiro de Sá, M.E., Langoni, H. e Funari, S.R.C. 2004a. Efeito do extrato alcoólico de própolis sobre o perfil bioquímico e o desempenho de coelhos jovens. Acta Scient. Anim. Sci., 26: 57-67.

Garcia, R.C., Pinheiro de Sá, M.E., Langoni, H. e Funari, S.R.C. 2004b. Efeito do extrato alcoólico de própolis sobre a Pasteurella

Archivos de zootecnia vol. 59 (R), p. 108. 


\section{A PRÓPOLIS E SUA UTILIZAÇÃO EM ANIMAIS DE PRODUÇÃO}

multocida in vitro e em coelhos. Acta Sci., Anim. Sci., 26: 69-77.

Ghisalberti, E.L. 1979. Propolis: a review. Bee World, 60: 59-84.

Giroux, S., Guy-Pierre, M. and Robert, S. 2000. Relationships between individual behavioural traits and post-weaning growth in segregated early-weaned piglets. Appl. Anim. Behav. Sci., 70: $41-48$

Hashimoto, J.H., Alcalde, C.R., Zambom, M.A., Silva, K.T., Macedo, F.A.F., Martins, E.N., Ramos, C.E.C.O. e Passianoto, G.O. 2007. Desempenho e digestibilidade aparente em cabritos Boer $x$ Saanen em confinamento recebendo rações com casca do grão de soja em substituição ao milho. Rev. Bras. Zootecn., 36: $174-182$.

Hogue, A.T., Ebel, E.D., Thomas, L.A., Schlosser, W., Bufano, N. and Ferris, K. 1997. Surveys of Salmonella enteritidis in unpasteurized liquid egg and spent hens at slaughter. J. Food Protect., 60: 1194-200.

Hollands, I., Miyares, C., Sigarroa, A. and Perez, A. 1984. Efficacy of propolis against infection by intestinal Eimeria in rabbits. Rev. Cubana Cienc. Vet., 15: 157-63.

Hollands, I., Miyares, C. and Sigarroa, A. 1988. Comparative analysis of action of propolis, sulphaquinoxalina and sulphamethazina in rabbits whith coccidiosis. Rev. Cubana Cienc. Vet., 19: 99-104.

Hollands, I., Pimienta, R. y Miyares, C. 1989. El propoleo y sus posibilidades en el tratamiento de la coccidiosis del conejo. In: Asis, M. (Ed.). Investigaciones cubanas sobre el propoleo: Memorias del $1^{\circ}$ Simposio sobre los efectos del propoleo en la salud humana y animal. Consejo Científico del Instituto de Medicina Veterinária. 1988. Varadero. Matanzas. Cuba. pp.100-108.

Ichikawa, M., Ichikawa, T. and Mizomoto, T. 1996. Productivity of enterotoxins and toxic shock syndome toxin-1, and coagulase type of Staphylococcus aureus strains isolated from bovines and humans in the same district. Anim. Sci. Technol., 67: 780-786.

Kartal, M., Kaya, S. and Kurucu, S. 2002. GC-MS analysis of propolis samples from two different regions of Turkey. Z. Naturforsch., 57: 905909 .

Kelley, T.R., Pancorbo, O.C., Merka, W.C. and
Barnharts, H.M. 1998. Antibiotic resistance of bacterial litter isolates. Poultry Sci., 77: 243247.

Koo, H., Rosalen, P.L., Cury, J.A., Park, Y.K., Ikegaki, M. and Sattler, A. 1999. Effect of Apis mellifera $\mathrm{L}$. propolis from two Brasilian regions on caries development in desalivated rats. Caries Res., 33: 393-400.

Lana, R.P., Camardelli, M.M.L., Queiroz, A.C., Rodrigues, M.T., Eifert, E.C., Miranda, E.N. e Almeida, I.C.C. 2005(a). Óleo de soja e própolis na alimentação de cabras leiteiras. Rev. Bras. Zootecn., 34: 650-658.

Lana, R.P., Camardelli, M.M.L., Rodrigues, M.T., Eifert, E.C., Oliveira, M.V.M., Stradiotti Júnior, D. e Oliveira, J.S. 2007(b). Óleo de soja e própolis na alimentação de cabras leiteiras: consumo de matéria seca e de nutrientes e parâmetros de fermentação ruminal. Rev. Bras. Zootecn., 36: 191-197.

Langoni, H., Domingues, P.F., Funari, S.R.C., Chande, C.G. e Neves, I.R. 1996. Efeito antimicrobiano in vitro da própolis. Arq. Bras. Vet. Zootec., 48: 227-229.

Langoni, H., Cabral, K.G., Domingues, P F., Pulga, M.E., Marinho, M. e Pardo, R B. 2000. Utilização da enrofloxacina (Baytril ${ }^{\circledR}$ ) no tratamento da mastite bovina estafilocócica. Cienc. Rural, 30: 167-170.

Laranja, L.F. e Machado, P.F. 1994. Ocorrência de mastite bovina em fazendas produtoras de leite B no estado de São Paulo. Sci. Agric., 51: 578585.

Lima, S.L. e Agostinho, C.A.A. 1992. Tecnologia de criação de rãs. Ed. Imprensa Universitária/ UFV. Viçosa. $168 \mathrm{pp}$.

Loguercio, A.P., Groff, A.C.M., Pedrozzo, A.F., Witt, N.M., Silva, M.S. e Vargas, A.C. 2006. Atividade in vitro do extrato de própolis contra agentes bacterianos da mastite bovina. Pesq. Agropec. Bras., 41: 347-349.

Marcucci, M.C. 1995. Propolis, chemical composition, biological properties and therapeutic activity. Apidologie, 26: 83-99.

Marcucci, M.C. 1996. Propriedades biológicas e terapêuticas dos constituintes químicos da própolis. Quími. Nova, 5: 529-536.

Marcucci, M.C., Ferreres, F. and Custódio, A. 2000. Evaluation of phenolic compounds in Brazilian propolis from different geographic

Archivos de zootecnia vol. 59 (R), p. 109. 


\section{COELHO, SILVA, OLIVEIRA, AMÂNCIO, SILVAE LIMA}

regions. Z. Naturforsch., 55: 76-81.

Matsuno, T. 1995. A new clerodane diterpenoid isolated from propolis. Z. Naturforsch., 50: 9397.

Mazzuco, H., Silva, R.D.M., Berchieri Jr. A. e Oliveira, E. 1996. Utilização da própolis e álcool etílico no controle de salmonella em rações avícolas. Sci. Agric., 53: 1-7.

Meresta, L., Meresta, T., Burdzinski, J. and Chmurzynski, P. 1989. Treatment of mastitis in cows using an extract of propolis. Medycyna Weterinaryjna, 45: 392-395.

Miles, R.D., Butcher, G.D., Henry, P.R. and Littell, R.C. 2006. Effect of antibiotic growth promoters on broiler performance, intestinal growth parameters, and quantitative morphology. Poultry Sci., 85:476-485.

Ministério da Agricultura. Brasil. 2001. Instrução Normativa $n^{\circ} 3$ - ANEXO VI - Regulamento técnico para fixação de identidade e qualidade de própolis. Diário Oficial da República Federativa do Brasil. Brasília. 19 jan.

Mirzoeva, O.K., Grishanin, R.N. and Calder, P.C. 1997. Antimicrobial action of propolis and some of its components: the effects on growth, membrane potencial and motility of bacteria. Microbiol. Res., 152: 239-246.

Moura, L.P.P., Scapinello, C., Martins, E.N., Franco, S.L. e Ribeiro, M.C.M. 1998. Efeito da solução hidroalcoólica de própolis e robenidina sobre a contagem de oocistos por grama de fezes de Eimeria spp. em coelhos Nova Zelândia Branco. Rev. Bras. Zootecn., 27: 325-30.

Mundim, A.V., Costa, A.S., Mundim, S.A.P., Guimarães, E.C. eEspindola, F.S. 2007. Influência da ordem e estádios da lactação no perfil bioquímico sangüíneo de cabras da raça Saanen. Arq. Bras. Med. Vet. Zootec., 59: 306-312.

Murad, J. M., Calvi, S. A., Soares, A.M. Bankova, V. e Sforcin, J.M.2002. Effects of propolis from Brazil and Bulgaria on fungicidal activity of macrophages against Paracoccidioides brasiliensis. J. Etnopharmacol., 79: 331-334.

Oetting, L.L., Utiyama, C.E., Giani, P.A., Ruiz, U.S. e Miyada, V.S. 2006. Efeitos de antimicrobianos e extratos vegetais sobre a microbiota intestinal e a freqüência de diarréia em leitões recémdesmamados. Rev. Bras. Zootecn., 35: 20132017.

Oliveira, J.S., Lana, R.P., Borges, A. C. Queiroz,
A.C. e Almeida, I.C.C. 2004. Efeito da monensina e extrato de própolis sobre a produção de amônia e degradabilidade in vitro da proteína bruta de diferentes fontes de nitrogênio. Rev. Bras. Zootecn., 33: 504-510.

Oliveira, T.T., Nagem, T.J. e Ribeiro, J.N. 2005. Análise sérica das enzimas aspartato aminotransferase, alanina aminotransferase e gama glutamiltranspeptidase de coelhos adultos tratados com extrato bruto de própolis. Rev. Cienc. Farm. Básica Apl., 26: 25-28.

Oliveira, J.S., Queiroz, A.C., Lana, R.P., Mantovani, H.C. e Generoso, R.A.R. 2006. Efeito da monensina e da própolis sobre a atividade de fermentação deaminoácidos in vitro pelos microrganismos ruminais. Rev. Bras. Zootecn., 35: 275-281.

Orsi, R.O., Sforcin, J.M., Rall, V.L.M., Funari, S.R. C., Barbosa, L. e Fernandes JR, A. 2005. Susceptibility profile of Salmonella against the antibacterial activity of propolis produced in two regions of Brazil. J. Venom. Anim. Toxins incl. Trop. Dis., 11: 109-116.

Orsi, R.O., Sforcin, J.M., Funari, S.R.C., Fernandes JR, A., Rodrigues, P. e Bankova, V. 2007. Effects of propolis from Brazil and Bulgaria on Salmonella serovars. J. Venom. Anim. Toxins incl. Trop. Dis., 13: 748-757.

Paes, P.R.O., Lopes, S.T.A., Lopes, R.S., Kohayagawa, A., Takahira, R.K. e Langoni, H. 2003. Efeitos da administração de vitamina $E$ na infecção mamária e na contagem de células somáticas de cabras primíparas desafiadas experimentalmente com Staphylococcus aureus. Arq. Bras. Med. Vet. Zootec., 55: 15-20.

Park, Y.K., Koo, M.H., Sato, H.H. e Contado, J.L. 1995. Estudo de alguns componentes da própolis coletada por Apis mellífera L. no Brasil. Arq. Biol. Tecnol., 38: 1253-1259.

Park, Y.K. Alencar, S.M., Scamparini, A.R.P. e Aguiar, C.L. 2002(a). Própolis produzida no sul do Brasil, Argentina e Uruguai: Evidências fitoquímicas de sua origem vegetal. Cienc. Rural, 32: 997-1003.

Park, Y.K., Alencar, S.M. and Aguiar, C.L. 2002(b). Botanical origin and chemical composition of Brazilian propolis. J. Agric. Food Chem., 50: 2502-2506.

Pedroso, A.A., Oetting, L.L., Utiyama, C.E., Menten, J.F.M., Lambais, M.R. e Miyada, V. S. 2005.

Archivos de zootecnia vol. 59 (R), p. 110. 


\section{A PRÓPOLIS E SUA UTILIZAÇÃO EM ANIMAIS DE PRODUÇÃO}

Variabilidade espacial da comunidade bacteriana intestinal de suínos suplementados com antibióticos ou extratos herbais. Rev. Bras. Zootecn., 34: 1225-1233.

Pereira, A.R., Machado, P.F. e Sarríes, G.A. 2001. Contagem de células somáticas e características produtivas de vacas da raça Holandesa em lactação. Sci. Agric., 58: 649-654.

Pereira, A.S., Seixas, F.R.M.S. e Aquino Neto, F.R. 2002. Própolis: 100 anos de pesquisa e suas perspectivas futuras. Quim. Nova, 25: 321326.

Pietta, P.G., Gardana, C. and Pietta, A.M. 2002. Analytical methods for quality control of própolis. Fitoterapia, 73: S7-S20.

Pinto, M.S., Faria J.E., Message, D., Cassini, S.T.A., Pereira, C.S. e Gioso, M.M. 2001. Efeito de extratos de própolis verde sobre bactérias patogênicas isoladas do leite de vacas com mastite. Braz. J. Vet. Res. Anim. Sci., 38: 278283.

Robert, S., Weary, D.M. and Gonyou, H. 1999. Segregated early weaning and welfare of piglets. J. Appl. Anim. Welfare Sci., 2: 31-40.

Rodrigues, C.A.F. Rodrigues, M.T., Branco, R.H., Silva, M.M.C., Torres-Filho, R.A. e Queiroz, A.C. 2007. Consumo, digestibilidade e produção de leite de cabras leiteiras alimentadas com dietas contendo diferentes níveis de proteína bruta e energia líquida. Rev. Bras. Zootecn., 36: 16581665.

Rodríguez-Serna, M., Flores-Nava, A., OliveraNovoa, M.A. and Carmona-Osalde, C. 1996. Growth and production of bullfrog Rana catesbeiana Shaw, 1802, at three stocking densities in a vertical intensive culture system. Aquacul. Engineer., 15: 233-242.

Russo, C., Preziuso, G., Paci, G., Campodoni, G. aand Marzoni, M. 1998. Effetto della linea paterna, dell'età di macellazione e del sesso sul profilo acidico della carne di coniglio. Riv. Coniglicoltura, 35: 29-32.

Sanchez, M. y Galardi, R. 1989. Influencia del propoleo en la conversión de lechones destetados. In: Asis, M. (ed.). Investigaciones cubanas sobre el propoleo: Memorias del $1^{\circ}$ Simposio sobre los efectos del propoleo en la salud humana y animal, 1988. Consejo Científico del Instituto de Medicina Veterinária. Varadero. Matanzas. Cuba. pp. 211-214.
Scandolera, A.J., Thomaz, M.C., kronka, R.N., Budiño, F.E.L., Fraga, A.L., Huaynate, R.A.R., Ruiz, U.S. e Cristani, J. 2008. Hidrolisados protéicos de mucosa intestinal, levedura e proteína isolada de soja em dietas com leite em pó integral para leitões desmamados. Rev. Bras. Zootecn., 37: 2355-2368.

Scapinello, C., Moura, L.P.P., Martins, E.N., Franco, S.L. e Ribeiro, M.C.M. 1998. Efeito da solução hidroalcoólica de própolis e robenidina no desempenho de coelhos em crescimento. Rev. Bras. Zootecn., 27: 150-156.

Silva, L.P. e Nörnberg, J.L. 2003. Prebióticos na nutrição de não ruminantes. Cienc. Rural, 33: 983-990.

Silva, R.A., Evangelista-Rodrigues, A., Ribeiro, M. C.M., Custódio, A.R., Andrade, N.E.D. e Pereira, W.E. 2006. Características físico-químicas e atividade antimicrobiana de extratos de própolis da Paraíba, Brasil. Cienc. Rural, 36: 1842-1848.

Silva, A.M.R., Berto, D.A., Lima, G.J.M.M., Wechsler, F.S., Padilha, P.M. e Castro, V.S. 2008. Valor nutricional e viabilidade econômica de rações suplementadas com maltodextrina e acidificante para leitões desmamados. Rev. Bras. Zootecn., 37: 286-295.

Souza Jr, F.L., Artigas, P.T. and Martins, M.L. 1993. Longibucca catesbeiana n. sp. Nematoda: Cylindrocorporidae, a gastrointestinal parasite of the bullfrog Rana catesbeiana Shaw, 1802 in Brazil. Singapore Med. J., 53: 97-102.

Stangaciu, S. 1998. Composición y propiedades del propóleos. Apimondia-Apiacta, 33: 71-77.

Stradiotti Jr, D., Queiroz, A.C., Lana, R.P., Pacheco,C.G., Camardelli, M.M.L., Detmann, E., Eifert, E.C., Nunes, P.M.M. e Oliveira, M.V.M. 2004. Ação do extrato de própolis sobre a fermentação in vitro de diferentes alimentos pela técnica de produção de gases. Rev. Bras. Zootecn., 33: 1093-1099.

Takaisi-Kikuni, N.B. aand Schilcher, H. 1994. Electron microscopic and microcalorimetric investigations of the possible mechanism of the antibacterial action of a defined propolis provenance. Planta Med., 60: 222-227.

Teh, T.H., Trung, L.T., Jia, Z.H., Gipson, T.A., Ogden, K. B. and Sweeney, T. F. 1994. Varying amounts of rumen-inert fat for high producing goats in early lactation. J. Dairy Sci., 77: 253258.

Archivos de zootecnia vol. 59 (R), p. 111. 


\section{COELHO, SILVA, OLIVEIRA, AMÂNCIO, SILVAE LIMA}

Timmermans Jr., S.J., Johnson, L.M. and Harrison, J.H. 2000. Estimation of the flow of microbial nitrogen using milk uric acid or allantoin. J. Dairy Sci., 83: 1286-1299.

Tinôco, I.F.F. 2001. Industrial: Novos conceitos de materiais, concepções e técnicas construtivas disponíveis para galpões avícolas brasileiros. Rev. Bras. Cienc. Avic., 3: 01-26.

Valdes, G., Ruiz, M. and Martin, M. 1989. Antibacterial characterization of propolis from Madruga and Mariel municipalities in the Province of Havana. Ciencia y Tecnica en la Agricultura. Apicultura, 5: 25-37.

Vargas, A.C. Loguercio, A.P., Witt, N.M., Costa, M.M., Silva, M.S. e Viana, L.R. 2004. Atividade antimicrobiana in vitro de extrato alcoólico de própolis. Cienc. Rural, 34: 159-163.

Vassalo, M., Fialho, E.T., Oliveira, A.I.G., Teixeira, A.S. e Bertechine, A.G. 1997. Probióticos para leitões dos 10 aos $30 \mathrm{~kg}$ de peso vivo. Rev. Soc. Bras. Zootecn., 1: 131-138.

Wollenweber, E. and Buchmann, S.L. 1997. Feral honey bees in the Sonoran Desert: propolis sources other than poplars (Populus spp.). $Z$. Naturforsch., 52: 530-535.

Zeoula, L.M., Beleze, J.R.F., Geron, L.J.V., Maeda, E.M., Prado, I.N. e Paula, M.C. 2008. Digestibilidade parcial e total de rações com a inclusão de ionóforo ou probiótico para bubalinos e bovinos. Rev. Bras. Zootecn., 37: 563-571.

Archivos de zootecnia vol. 59 (R), p. 112. 